\title{
Biocontrol activity of siderophore producing Bacillus subtilis CTS-G24 against wilt and dry root rot causing fungi in chickpea.
}

\author{
${ }^{1}$ Santosh Patil, ${ }^{2}$ Mallikarjun C Bheemaraddi, ${ }^{3}$ Channappa T. Shivannavar, \\ ${ }^{4}$ Subhashchandra M Gaddad \\ 1,2,3,4 (Department of Microbiology, Gulbarga University, Gulbarga 585106, Karnataka, India)
}

\begin{abstract}
Siderophore producing bacteria as biocontrol agent may play a pivotal role in controlling several fungal pathogens which causes plant diseases. Fusarium oxysporium f. sp. ciceri (FOC) and Macrophomina phaseolina are major phytopathogens amongst the several constraints affecting the productivity of chickpea in India and other countries in Asia. In the present study, indigenous Bacillus subtilis CTS-G24, (Partial $16 \mathrm{~S}$ rRNA sequence of Bacillus subtilis is deposited in GenBank with accession number KF322037) was detected positive for siderophore production. Antiphytopathogenic activity of strain CTS-G24 against wilt and dry root rot causing FOC and M. phaseolina respectively was checked. It was revealed that Hydroxamate type of siderophore was produced by CTS-G24 and $64 \%$ of siderophore units was produced in Succinate medium by Bacillus subtilis CTS-G24. Plant Growth Promoting Rhizobacteria (PGPR) are known to influence plant growth by suppressing plant disease and might be applied in agriculture as an alternative to chemical pesticides for improving the quality and yield of crop. Siderophores produced by Bacillus subtilis has got the potentials to control plant diseases in chickpea.
\end{abstract}

Keywords: Bacillus subtilis, Siderophore, Cicer arietinum, Fusarium wilt, Dry root rot

\section{Introduction}

Chickpea (Cicer arietinum) are the major pulse crops of India. Chickpea is largely grown in arid and semi-arid environments in Asia and Africa and it is valued for its nutritive seeds with high protein content. Chickpea is one of the major important agricultural crops of this region which are prone to many soil borne plant pathogens, reducing the quality and quantity of their yield. Fungicides are the primary means of fungal disease control, but their use is currently controversial because, the investigators have indicated potential undesirable environmental side effects [1].

In most agriculture ecosystems, soil borne plant pathogens can be a major limitation to the production of marketable yields. Microorganisms that adversely affect plant growth and health are the pathogenic fungi, oomycetes, bacteria and nematodes [2]. The rapidly multiplying population is exerting immense pressure on agricultural lands for more crop yields, which results in more and more extensive use of chemical fertilizers and pesticides [3]. The long residual action and toxicity of the chemical pesticides have brought about serious environmental problems such as mammalian toxicity, and accumulation of pesticide residues in the food chain [4]. Strict regulations have been imposed upon the use of chemical pesticides and mounting political pressure to remove the hazardous chemicals, has created a renewed interest in environmentally friendly alternatives. The use of plant growth- promoting bacteria with antifungal properties is an attractive alternative to the use of such xenobiotic compounds [5]. All these conditions have highlighted the need for alternative biological control agents. Non-pathogenic soil bacteria having the ability to antagonize fungal phytopathogens have emerged as an important alternative in managing soil borne plant diseases. Several rhizobacteria also called as Plant GrowthPromoting Rhizobacteria (PGPR) exert their beneficial effect on plants by various mechanisms viz. siderophore production, $\mathrm{HCN}$, antibiotics, lytic enzymes, competing for colonization sites, nutrients and by inducing systemic resistance $[6,1,2,8]$.

Siderophores are the iron-chelating compounds produced by many microorganisms growing under iron-limiting conditions and these are the low molecular weight $(<1,000 \mathrm{Da})$ small peptide molecules [9]. Bacterial siderophores are low-molecular-weight compounds with high $\mathrm{Fe}^{3+}$ chelating affinity [10] responsible for the solubilization and transport of this element into bacterial cells. Some bacteria produce hydroxamate-type siderophores, while others produce catecholate-types [11]. Siderophore produced by bacteria's have been employed efficiently as biocontrol agents against certain soil-borne plant pathogens. Siderophores drastically reduce the amount of ferric ions available to certain rhizosphere microflora and inhibits the growth of the fungus [12]. Siderophores are useful in agriculture for plant disease management and also in plant growth improvement [13]. PGPR activity has been reported in bacterium strains belonging to several genera, such as Acetobacter sp, Azospirillum sp, Azotobacter sp, Bacillus sp, Burkholderia sp and Pseudomonas sp [1,8]. There has been an increasing interest among microbiologists to use beneficial microorganisms as a solution for the overuse of potentially harmful pesticides [14-16]. Therefore, in this present study it was aimed to examine the siderophore 
producing Bacillus subtilis strain for antiphytopathogenic activity. Furthermore, characterization and estimation of siderophore produced in different medium by the test strain is also presented.

\section{Materials and Methods}

2.1 Chemicals and Glassware

All chemicals were of analytical grade and purchased from Himedia Laboratories Pvt. Ltd (Mumbai, India), otherwise indicated elsewhere in the text. All glassware's used were cleaned in $20 \% \mathrm{HCl}$ to remove iron traces and rinsed in deionized water.

\subsection{Microorganisms}

Bacillus subtilis CTS-G24 used in the present study was isolated from the rhizospheric soil sample collected from Gulbarga region and maintained in our laboratory. Partial $16 \mathrm{~S}$ rRNA sequence analysis of the isolate CTS-G24 exhibited 99\% homology with Bacillus subtilis and the sequence was deposited in GenBank with accession number KF322037. Agriculture Research Station (ARS) at Gulbarga, Karnataka, India, generously provided of Fusarium oxysporum $f$. sp. ciceri (FOC) and M. phaseolina which were previously isolated from infected chickpea plants showing the symptoms of wilt and dry root rot respectively. After retrieving fungal and bacterial strains they were maintained on Potato Dextrose Agar (PDA) and Nutrient Agar (NA) media for further studies.

\subsection{Detection of siderophore production on CAS agar media}

Detection of siderophore was performed on the Chromeazurol (CAS) agar assay media as described by Schwyn and Neilands [17], with slight modifications [18]. Briefly, $60.5 \mathrm{mg}$ of CAS was dissolved in $50 \mathrm{~mL}$ of deionized water, and mixed with $10 \mathrm{~mL}$ of a $\mathrm{Fe}^{3+}$ solution $\left(1 \mathrm{mmol} \mathrm{L}^{-1} \mathrm{FeCl}_{3} \cdot 6 \mathrm{H}_{2} \mathrm{O}, 10 \mathrm{mmol} \mathrm{L}^{-1} \mathrm{HCl}\right)$. While stirring, this solution was slowly mixed with $72.9 \mathrm{mg}$ of hexadecyltrimethylammonium bromide (HDTMA) previously dissolved in $40 \mathrm{~mL}$ water. The resulting dark-blue solution was autoclaved, cooled brought upto $50 / 60^{\circ} \mathrm{C}$ and mixed with $900 \mathrm{~mL}$ sterile MM9 [18] containing $15 \mathrm{~g} \mathrm{~L}^{-1}$ agar (also kept at 50/60 ${ }^{\circ} \mathrm{C}$ ). After solidification of the media on Petri plates, bacterial strain was inoculated and incubated in the dark $\left(28^{\circ} \mathrm{C}\right.$ for 5 days). Formation of yellow orange zone around the colonies from dark blue indicated positive result.

\subsection{Characterization of Siderophores}

The characterization of the siderophore as catechol or hydroxamate types was carried out as follows,

\subsubsection{Hydroxamate Type of Siderophore}

The hydroxamate nature of siderophore was detected by Neilands spectrophotometric assay where a peak between $420-450 \mathrm{~nm}$ on addition of $2 \%$ aqueous solution of $\mathrm{FeCl}_{3}$ to $1 \mathrm{ml}$ of cell-free supernatant indicated the presence of Ferrate hydroxamate [19].

\subsubsection{Catecholate Type of Siderophore}

Catecholate siderophores were detected by spectrophotometric assay, where a peak at $495 \mathrm{~nm}$ on addition of $2 \%$ aqueous solution of $\mathrm{FeCl}_{3}$ to $1 \mathrm{ml}$ of cell-free supernatant indicated the presence of catecholate siderophore [20].

\subsection{Production of Siderophore in Different Media}

For production of siderophores, Nutrient broth and Succinate medium were separately inoculated with B. subtilis CTS-G24 and incubated. in which strain was grown in Succinate and Nutrient medium and incubated for $24-30 \mathrm{hrs}$ at $28^{\circ} \mathrm{C}$ with constant shaking at $120 \mathrm{rpm}$ on shaking incubator separately. The siderophore contents were measured by quantitative CAS assay [21]. During incubation, aliquots of media were removed every 4 hours and centrifuged at $10000 \mathrm{rpm}$ for $10 \mathrm{~min}$; the cell free supernatants were subjected to detection of siderophore

\subsection{Estimation of Siderophore}

The quantitative estimation of siderophore produced by B. subtilis CTS-G24 was done by CAS-shuttle assay. During incubation, every $4 \mathrm{hrs} 5 \mathrm{ml}$ broths were centrifuged at $10,000 \mathrm{rpm}$ at $4^{\circ} \mathrm{C}$ in cooling centrifuge for 10 minute and cell free supernatant was mixed with $0.5 \mathrm{ml} \mathrm{CAS} \mathrm{solution.} \mathrm{A} \mathrm{reference} \mathrm{solution} \mathrm{was} \mathrm{prepared}$ with uninoculated media and CAS assay solution. The sample and reference absorbance were measured at 630 $\mathrm{nm}$ after $1 \mathrm{~h}$ of incubation at room temperature. The color obtained was measured using the spectrophotometer at $630 \mathrm{~nm}$ with reference containing $0.5 \mathrm{ml}$ uninoculated medium and $0.5 \mathrm{ml}$ CAS solution.

The percentage of siderophore units was estimated as the proportion of CAS color shifted using the formula: \% Siderophore units $=[(\mathrm{Ar}-\mathrm{As}) / \mathrm{Ar}] \mathrm{x} 100,(1)$ where "Ar" is the absorbance at $630 \mathrm{~nm}$ of reference 
(CAS assay solution+ uninoculated media) and "As" is the absorbance at $630 \mathrm{~nm}$ of the sample (CAS assay solution + supernatant) [21].

\subsection{In vitro antagonistic assay}

Gram positive, spore forming rhizobacterial strain Bacillus subtilis was subjected for antagonistic activity against phytopathogenic strains of FOC and M. phaseolina using dual culturing technique as described by Foldes et al., [22] with some modification. The fungus was point inoculated at the centre of Petri-dishes with PDA (pH 6) and cultivated at $28^{\circ} \mathrm{C}$ for three days. Approximately, $4 \mathrm{~cm}$ from the actively growing mycelium of mould, test strain was inoculated with a single streak. Petri dishes were incubated at $28^{\circ} \mathrm{C}$ for seven days as periodically they were checked for inhibition of pathogenic growth indicated by formation of a clear zone. The control Petri dishes with mould fungi were seeded without being inoculated with Bacillus isolates.

\section{Results and Discussions}

3.1 Detection and characterization of siderophore

Siderophore production by B. subtilis CTS-G24 was confirmed by developing yellow to orange colored zone on blue coloured CAS agar plate indicating siderophore production. The color change from blue to orange was the result of siderophoral removal of Fe from the dye (Fig. 1), which is also an indicative of a hydroxymate type of siderophore [23]. As expected, no colour change was observed in the uninoculated plates after incubation for 3 weeks. Similar finding have been reported by several workers [24, 25]. Spectrophotometric analysis of the culture in standard succinate medium showed a peak between 420 to $450 \mathrm{~nm}$ (Fig. 2) indicated the presence of siderophores of ferrate hydroxamate nature by B. subtilis.

\subsection{Siderophore production in liquid media}

The color change from blue to orange resulted by siderophoretic removal of Fe from the dye [17]. The maximum siderophoregenesis was obtained on succinate medium as compared to nutrient media. In quantitative CAS assay, percent siderophore units were estimated as the proportion of CAS color shifted. It was found that B. subtilis CTS-G24 produced $64 \%$ and $59 \%$ siderophore units in Succinate and Nutrient media respectively (Fig. 3). Siderophores are iron-specific compounds which are secreted under low iron stress conditions. In the succinate medium, the maximum siderophore production was found by B. subtilis CTS-G24 without the addition of iron while its productivity may be repressed due to presence of iron traces in Nutrient medium.

Siderophore primarily help the producing organism in iron acquisition under iron-limiting conditions. Buyer et al., (1993), using monoclonal antibodies, confirmed the production of siderophore by PGPR in rhizosphere under iron-limiting conditions. Purified siderophores had disease-suppressive effect similar to the producer strain $[12,27]$. A siderophore over-producing mutant of Pseudomonas putida was more effective than the wilt type in control of Fusarium wilt of tomato [28], while a siderophore-deficient mutant of P. aeruginosa lost its biocontrol ability [29]. In a state of iron limitation, the siderophore-producing microorganisms are also able to bind and transport the iron-siderophore complex by the expression of specific proteins [30, 31]. The production of siderophores by microorganisms is beneficial to plants, because it can inhibit the growth of plant pathogens [32].

\subsection{In vitro antagonistic activity of bacterial strains against soil-borne fungal pathogens}

In a dual culture assay for fungicidal activity of Bacillus subtilis CTS-G24 against FOC and $M$. phaseolina, strain CTS-G24 vigorously inhibited the growth of the phytopathogenic fungi. After the additional incubation period of 10 days, the pathogenic mycelia did not cover the surface of the inhibition ring, which indicates the antagonism was very strong [22]. The results of further antagonistic tests showed that CTS-G24 had the sterilizing or inhibitory effect on tested phytopathogens (Fig. 4). Antagonistic test revealed that the confluent growth of bacteria inhibited the development of fungal phytopathogens. Production of chickpea in India and other countries in Asia is severely affected by many plant pathogenic fungi, bacteria, virus and nematodes which cause the diseases such as Fusarium wilt, dry root rot, ascochyta blight, collar rot, bacterial blight, filiform virus and dirty root nematode. Among the several constraints affecting the productivity of chickpea, $10-25 \%$ loss in the yields are due to wilt and dry root rot diseases caused by FOC and M. phaseolina [33].

B. subtilis exhibited clear antagonistic activity when checked against wilt and dry root rot causing agents (Fig. 4). B. subtilis, which is ubiquitous in soil, are amongst beneficial rhizobacterium that can promote plant growth and protect against fungal pathogen attack [34]. Non pathogenic B. subtilis are most industrially significant bacterium and are considered as GRAS (Generally Recognized As Safe). They occur naturally in soil and rhizosphere of crop plants. These microorganisms' posses' potential biotechnological application and play crucial roles in the environment [34]. Literature on natural biological agents against phytopathogens revealed that Bacillus sps have emerged as potential antiphytopathogenic and PGP agent so far. Among the first 
successful biocontrol agents used against insects, and pathogens were members of the genus Bacillus. Bacillus strains are considered as safe biological control agents [4,35]. Intrinsic properties of Bacillus, such as, formation of oval endospores that remain dormant for a long period under unfavorable environmental conditions makes them potential colonizer [36].

IV

Conclusion

In vitro findings indicate the potential application of indigenous strain B. subtilis capable of producing Hydroxamate type of siderophore as biocontrol agents due to their efficacy to inhibit the phytopathogens. B. subtilis displayed pronounced antagonism against FOC and M. phaseolina, phytopathogens of chickpea. Abilities of bacterial isolates will be evaluated, in greenhouse conditions for controlling wilt and dry root rot diseases in the chickpea plants. We further conclude that, the use of B. subtilis CTS-G24 is antagonistic rhizobacterial isolates has biocontrol agents, will allow developing rational biocontrol agent for sustainable agriculture and research in this direction seems to be encouraging.

\section{Acknowledgement}

Authors are thankful to Department of Microbiology, Gulbarga University, Gulbarga, for providing the facilities to carry out the present investigation. Authors would also like to acknowledge, Dr. S. K. Jaya Laxmi, Faculty at College of Agriculture for kindly providing pure cultures fungal phytopathogens.

\section{References}

[1] J. Handelsman, and E. Stabb, Biocontrol of soil-borne plant pathogens, Plant Cell , 8(10), 1996, $1855-1869$.

[2] J. M. Raaijmakers, T. C. Paulitz, C. Steinberg, C. Alabouvette and Y. Moenne-Loccoz, The rhizosphere: a playground and battlefield for soilborne pathogens and beneficial microorganisms, Plant Soil, 321, 2009, 341-361.

[3] H. Karlidag, A. Esitken, M. Turan, and F. Sahin, Effects of root inoculation of plant growth promoting rhizobacteria (PGPR) on yield, growth and nutrient element contents of leaves of apple, Sci. Horticult., 114, 2007,16-20.

[4] M. A. El-Bendary, Bacillus thuringiensis and Bacillus sphaericus biopesticides production, J. Basic Microbiol., 46, 2006, 158-170.

[5] S. Compant, B. Duffy, J. Nowak, C. Clement and E. A. Barka, Use of plant growth-promoting bacteria for biocontrol of plant diseases: principles, mechanisms of action, and future prospects, Appl Envinon Microbiol., 71, 2005, 4951-4959.

[6] J. M. Whipps, Microbial interactions and biocontrol in the rhizosphere, J. Exp. Bot., 52, 2001, 487-511.

[7] C. L. Pattern, and B. R. Glick, Bacterial biosynthesis of indole- 3-acetic acid, Can. J. Microbiol., 42, 1996, 207-220.

[8] B. Lugtenberg and F. Kamilova, Plant-growth-promoting rhizobacteria, Annu. Rev. Microbiol., 63, 2009, 541-556.

[9] D. Suryalala, P. Umamaheswardevi and K. Vijayalakshmi, Chemical characterization and in vitro antibiosis of siderophore of rhizosphere fluorescent Pseudomonas, Indian J. Microbiol., 13, 2004, 105-108.

[10] A. Sharma and B. N. Johri, Growth promoting influence of siderophore-producing Pseudomonas strains GRP3A and PRS9 in maize (Zea mays L.) under iron limiting conditions, Microbiological Research, 158, 2003, 243-248.

[11] J. B. Neilands and K. Nakamura, Detection, determination, isolation, characterization and regulation of microbial iron chelates, in G. Winkelmann (Ed.), CRC handbook of microbial iron chelates, (Florida: CRC Press, 1991) 1-14.

[12] J. W. Kloepper, J. Leong, M. Teintze and M. N. Schroth, Enhanced plant growth by siderophores produced by plant growth promoting rhizobacteria, Nature (London), 286, 1980, 885-886.

[13] A. K. Patel, J. A. Ahire, S. P. Pawar, and B. L. Chaudhari, Evaluation of probiotic characteristics of siderophorogenic Bacillus spp. Isolated from dairy waste, Appl. Biochem. Biotechnol., 160, 2010, 140-155.

[14] D.R. Fravel, Role of antibiosis in the biocontrol of plant diseases, Annu. Rev. Phytopathol., 26, 1988, 75-91.

[15] N. Sakthivel and S. S. Gnanamanicham, Evaluation of Pseudomonas fluorescens for suppression of sheath rot diseases and for enhancement of grain yields in rice (Oryza sativa L.), Appl. Microbiol., 53, 1987, 2056-2059.

[16] D. M. Weller, Biological control of soil-borne plant pathogens in the rhizosphere with bacteria, Annu. Rev. Phytopathol., 73,1988, 463-469.

[17] B. Schwyn and J.B. Neilands, Universal chemical assay for the detection and determination of siderophores, Anal Biochem, 160, 1987, 47-56.

[18] M. E. Silva-Stenico, F. T. H. Pacheco, J. L. M. Rodrigues, E. Carrilho and S. M. Tsai, Growth and siderophore production of Xylella fastidiosa under iron-limited conditions, Microbiological Research, 160, 2005, 429-436.

[19] M. A. F Jalal and H. D. Vander, Isolation and spectroscopic identification of fungal siderophores, in G. Winkelmann (Ed.), Handbook of microbial iron chelates, (Britain, Pegamon Press, Oxford, 1990) 235-269.

[20] J. M. Meyer, D. Honhadel, A. Khan, and P. Cornelis, Pyoverdin-facilitated iron uptake in Pseudomonas Aeruginosa: immunological characterization of the ferripyoverdin receptor, Mol. Microbiol, 4, 1990, 1401-1405.

[21] S. M. Payne, Detection, isolation and characterization of siderophores, Methods Enzymol, 235, 1994, 329.

[22] T. Foldes, I. Banhegyi, Z. Herpai, L. Varga and J. Szigeti, Isolation of Bacillus strains from the rhizosphere of cereals and in vitro screening for antagonism against phytopathogenic, food-borne pathogenic and spoilage microorganisms, J. Appl. Microbiol., 89, $2000,840-846$.

[23] A. M. F. Milagres, A. Machuca and D. Napoleao, Detection of siderophore production from several fungi and bacteria by a modification of chrome azurol S (CAS) agar plate assay, J Microbiol Methods, 37, 1999, 1-6.

[24] A. Machuca and A. M. F. Milagres, Use of CAS-agar plate modified to study the effect of different variables on the siderophore production by Aspergillus, Lett Appl Microbiol 36, 2003, 177-181.

[25] M. B. Sulochana, S. Y. Jayachandra, S. Anil Kumar, A. B. Parameshwar, K. Mohan Reddy and A. Dayanand, Siderophore as a Potential Plant Growth-Promoting Agent Produced by Pseudomonas aeruginosa JAS-25, Appl Biochem Biotechnol, DOI.10.1007/s12010-014-1039-3

[26] J. S. Buyer, M. G. Kratzke and L. J. A. Sikora, Method for detection of pseudobactin, the siderophore produced by a plant-growthpromoting pseudomonas strain, in the barley rhizosphere, Appl Environ Microbiol, 59(3), 1993, 677-81.

[27] J. B. Neilands and S. A. Leong, Siderophores in relation to plant growth and disease, Annual Review of Plant Physiology 37,1986 , $187-208$. 
[28] P. A. Vandenburgh and C. F. Gonzalez, Methods for protecting the growth of plants by employing mutants siderophore producing strains of Pseudomonas putida. U.S. Patent No. 4479936, 1984.

[29] S. Buysens, J. Poppe and M. Hofte, Role of siderophores in the plant stimulation and antagonism by Pseudomonas aeruginosa 7NSK2. In: M. H. Ryder, P. M. Stephens, G. D. Bowen (eds), Improving plant productivity with rhizosphere bacteria, (Commonwealth Scientific and Industrial Research Organization, Adelaide, Australia, 1994) 139-141.

[30] L. Nachin, E. L. Hassouni, M. Loiseau, L. Expert, D. Barras and F. Sox, R-dependent response to oxidative stress and virulence of Erwinia chrysanthemi: the key role of SufC, an orphan ABC ATPase. Molecular Microbiology, 39, 2001, 960-972.

[31] C. Nudel, R. Gonzalez, N. Castaneda, G. Mahler and L. A. Actis, Influence of iron on growth, production of siderophore compounds, membrane proteins, and lipase activity in Acinetobacter calcoaceticus BD 413, Microbiological Research, 155, 2001, 263-269, 2001.

[32] A. Sharma and B. N. Johri, Growth promoting influence of siderophore-producing Pseudomonas strains GRP3A and PRS9 in maize (Zea mays L.) under iron limiting conditions, Microbiological Research,158, 2003, 243-248.

[33] M. Pal, Diseases of pulse crop, their relative importance and management, J. Mycol. Plant Pathol., 28 (2),1998,114-122.

[34] E. A. B. Emmert and J. Handelsman, Biocontrol of plant disease: a Grampositive perspective. FEMS. Microbiol. Lett., 171, 1999, $1-9$.

[35] K. A. Powell and A. R. Jutsum, Technical and commercial aspects of biological control products. Pestic. Sci., 37, 1993, 315-321

[36] D. Fritze, Taxonomy of the genus Bacillus and related genera: The aerobic endospore-forming bacteria. Phytopathology, 94, 2004, $1245-1248$.

\section{List of figures}

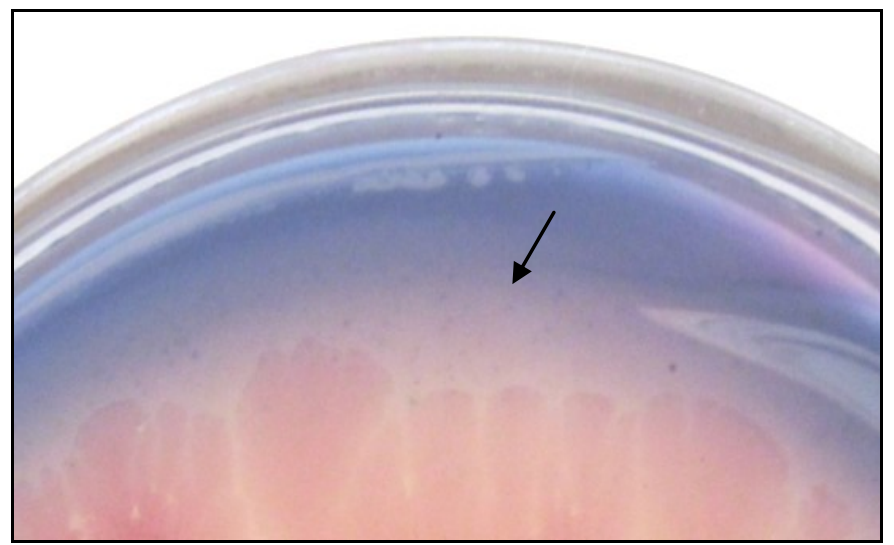

Figure 1. Siderophore production by Bacillus subtilis CTS-G24 was confirmed by color change of CAS reagent from blue to bark orange indicated by arrow.

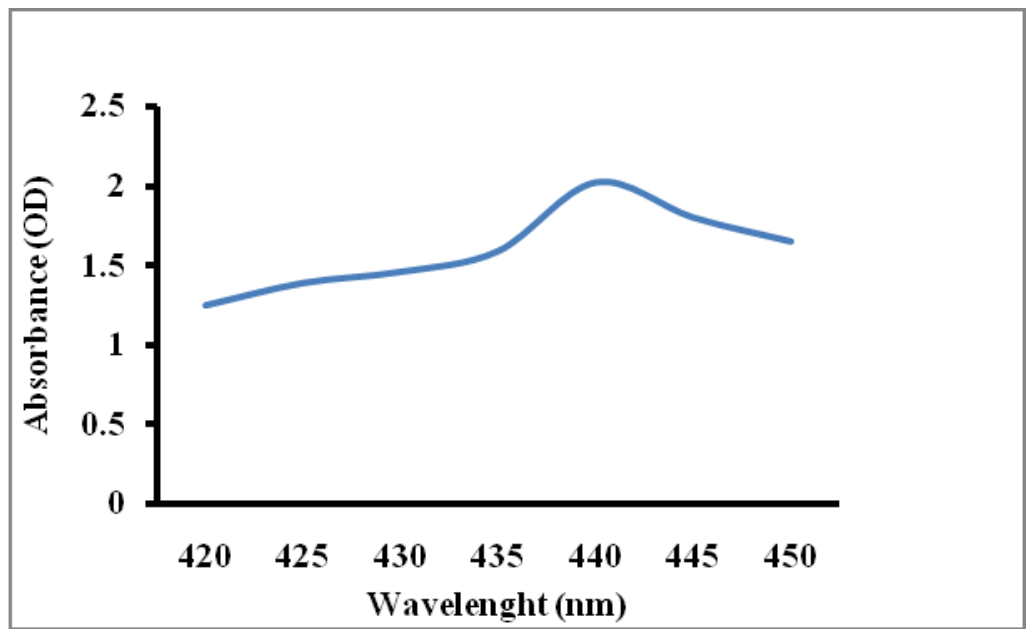

Figure 2. Absorption characteristics of B. subtilis media extracts confirming hydroxamate nature of siderophore. 


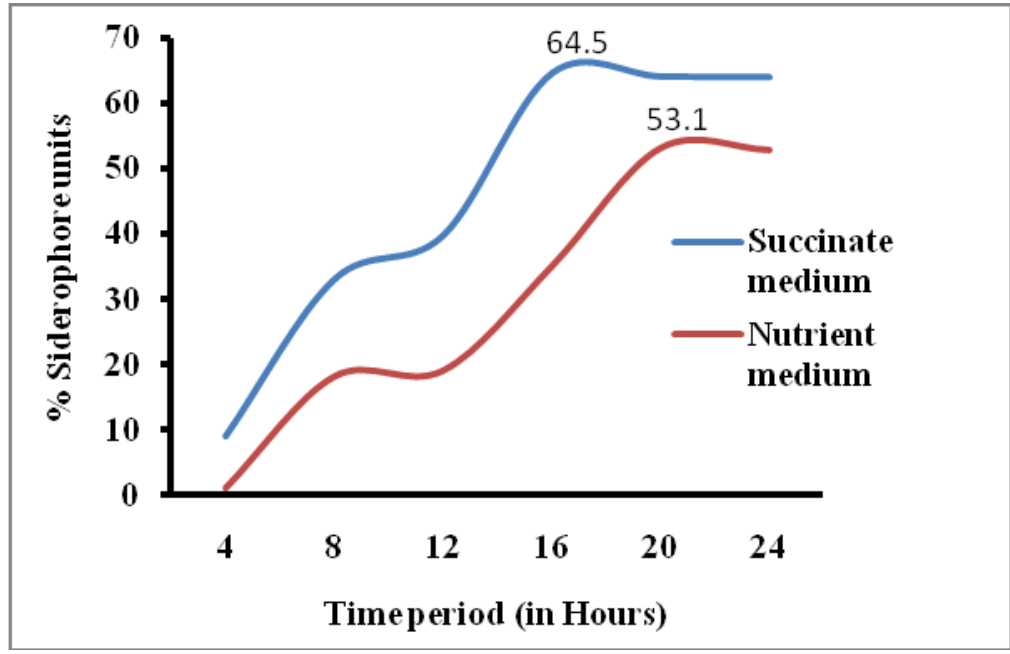

Figure 3. Effect of growth medium on siderophore production by B. subtilis CTS-G24
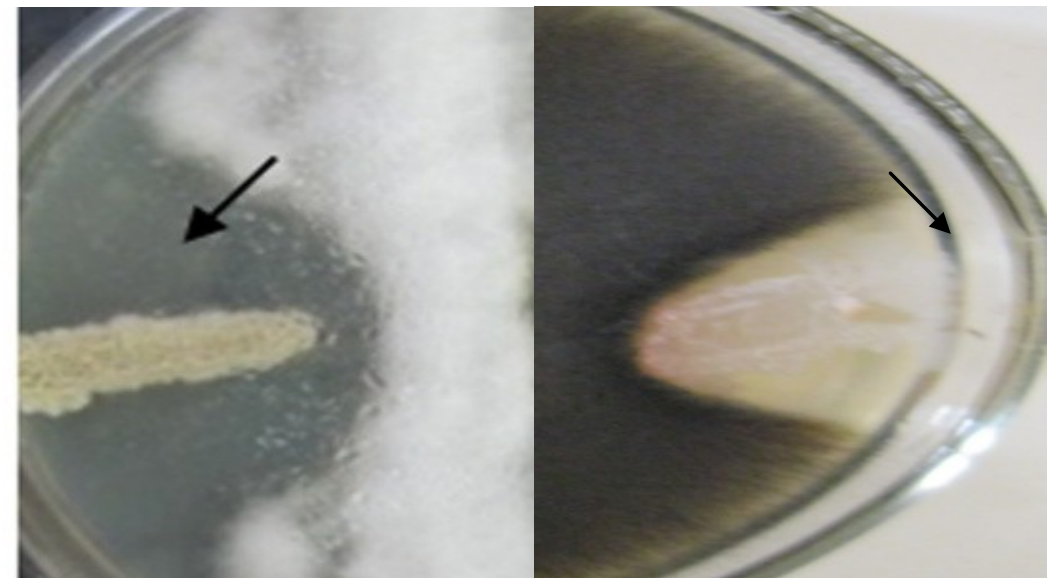

Figure 4. Antagonist activity of strain CTS-G24 against phytopathogens., (Right) Fusarium oxysporium $f . s p$. ciceri (FOC) and (Left) Macrophomina phaseolina (Arrows indicating the zone of inhibition of fungi by Strain CTS-G24). 